\title{
The Effectiveness of Topical Aid Sliding Sheet Potentially Used for Pressure Injury Treatment
}

This article was published in the following Dove Press journal:

Chronic Wound Care Management and Research

\author{
Masushi Kohta $\mathbb{D}^{\prime}$ \\ Yoshinori Nakamura ${ }^{2,3}$ \\ Shunji Yunoki ${ }^{4}$ \\ 'Medical Engineering Laboratory, \\ ALCARE Co., Ltd, Tokyo, Japan; \\ ${ }^{2}$ Department of Medical Home \\ Healthcare Center, Tenri Hospital \\ Shirakawa Branch, Nara, Japan; ${ }^{3}$ Pressure \\ Injury Research Center for Home \\ Healthcare, Nara, Japan; ${ }^{4}$ Biotechnology \\ Group, Tokyo Metropolitan Industrial \\ Technology Research Institute, Tokyo, \\ Japan
}

Purpose: This study evaluated the effect of a new secondary dressing used as a topical aid sliding sheet for friction and shear force reduction on the mechanical stresses generated on human skin, including interface friction and internal shear force and pressure, using a polyurethane gel-based skin model. A case study was conducted to propose on how to clinically use the topical aid sliding sheet for pressure injury treatment in a home-care setting.

Methods: A polyurethane gel-based skin model mimicking the mechanical properties of human skin was prepared. In parallel measurement of interface friction and internal shear force and pressure was performed using an experimental model consisting of the skin model, primary wound dressing, topical aid sliding sheet, and three-axis tactile sensor. The skin model was covered with the following single or combined dressings: group A, silicone-faced absorbent dressing (control); group B, silicone-faced absorbent dressing plus film dressing; and group $\mathrm{C}$, silicone-faced absorbent dressing plus topical aid sliding sheet. Clinically, a standard primary wound dressing was applied to a female patient (age, 101 years) with pressure injury on the sacral region, and the dressing was overwrapped with the topical aid sliding sheet.

Results: The static and dynamic coefficients of friction were significantly lower in group $\mathrm{C}$ than in groups $\mathrm{A}$ and $\mathrm{B}(p<0.05)$. The detected shear force in the skin model was reduced to approximately $66 \%$ and $62 \%$ in group $\mathrm{C}$ versus groups $\mathrm{A}$ and $\mathrm{B}$, respectively $(p<0.05)$. Clinically, the patient's ulcer underwent complete epithelialization without wound-related complications.

Conclusion: The topical aid sliding sheet significantly reduced interface friction and internal shear forces in the present skin model. The case study's result showed the topical aid sliding sheet had the potential to use for pressure injury treatment at a home care.

Keywords: pressure ulcer, tissue viability, dressing, mechanical force, wound care, shear force, friction

\section{Introduction}

Pressure injury, a localized skin injury resulting from a combination of mechanical forces, such as friction, shear force, and pressure, over a prolonged period of time, is a common chronic wound. ${ }^{1}$ These forces on the skin result in soft tissue deformation, followed by ischemic damage as the final common pathway to ulceration. ${ }^{2,3}$ An increase in the incidence or prevalence of pressure injury in healthcare settings is strongly associated with a wide spectrum of socioeconomic problems, including hospital clinical quality indicators, quality of life, and healthcare financial crises. ${ }^{4-6}$ A systematic review recently reported that the global point
Correspondence: Masushi Kohta Medical Engineering Laboratory, ALCARE Co., Ltd, I-2I-I0 Kyojima, Sumida-ku, Tokyo, I3I-0046, Japan

Tel +8I-3-36II-| I0I

Fax +8I-3-36I3-6894

Email mkouta@alcare.co.jp
Chronic Wound Care Management and Research 2021:8 I-II

(c) (5) () 202I Kohta et al. This work is published and licensed by Dove Medical Press Limited. The full terms of this license are available at https://www.dovepress.com/terms. C. ${ }_{\mathrm{BY}} \mathrm{NC}$ php and incorporate the Creative Commons Attribution - Non Commercial (unported, v3.0) License (http://creativecommons.org/licenses/by-nc/3.0/). By accessing the work you hereby accept the Terms. Non-commercial uses of the work are permitted without any further permission from Dove Medical Press Limited, provided the work is properly attributed. For permission for commercial use of this work, please see paragraphs 4.2 and 5 of our Terms (https://www.dovepress.com/terms.php). 
prevalence of pressure injury was $14.8 \%$ and the period prevalence was $11.6 \%$, whereas the mean incidence of pressure injury was $6.3 \%{ }^{7}$

Friction is usually generated on the interface of the skin site in individuals at risk of pressure injury development and/or on the interface of the wound site in individuals with existing pressure injury. When individuals drag their body across a surface, a constant rubbing, or pulling occurs on the skin and wound site. When individuals receive nursing assistance at the bedside (eg, head-of-bed elevation and repositioning), simple sliding and movement can create additional friction forces between bedsheets and the skin/wound site via clothing/wound dressings. ${ }^{8-11}$ This increases the risk of damaging more superficial tissue, whereas shear force with pressure will more likely damage the underlying tissue, resulting in further tissue damage accompanied by delayed wound healing. ${ }^{12}$ Repeated friction and pressure at wound area will possibly cause a break in the wound surface that allows pathogens to penetrate, and eventually generate secondary infection.

Although friction and shear force, in addition to pressure, are generated constantly, current clinical techniques for reducing these forces are limited. Physicians or nurses can usually check whether excessive pressure occurs by sliding their hands between the patient's wound site and bedsheets. Traditionally, nurses lift the patient's body to protect wounds under continuous pressure by the patient's own weight on the bed. ${ }^{10}$ Support surfaces, such as mattresses and cushions, are usually helpful in dispersing the excessive pressure on the body. ${ }^{13}$ To reduce the friction between bedsheets and the wound surface, a soft plastic material, such as sliding grooves or sheets, can be conventionally used when changing patient position. ${ }^{1,14}$ These assistive devices used by physicians or nurses are transiently, but not continuously, effective and may be insufficient for preventing and treating pressure injury.

Recently, a clinical guideline has recommended applying prophylactic dressing on skin sites predisposed to the development of a pressure injury. ${ }^{1}$ Several types of dressings, including hydrocolloid with a low-friction outer layer and multilayered silicone foam dressing, are commercially available, and are used clinically for prophylactic purposes as standard preventive care. ${ }^{15-17}$ Previous evidence from basic research strongly supports the effectiveness of dressings in clinical practice. Using an in vitro experimental model, Matsuzaki and Kishi investigated the pressure-reducing properties of silicone foam and thin hydrocolloid dressings in static condition. ${ }^{18}$ Moreover,
Ohura et al prepared another experimental model that consisted of porcine skin with a sensor capable of measuring the pressure and shear force. They reported that the film and hydrocolloid dressings were more effective in reducing shear force than hydropolymer and hydrocellular dressings. ${ }^{12}$ Call et al developed a measurement model they termed the shear displacement method and evaluated the shear force-reducing property of multilayered silicone foam dressings. ${ }^{19}$

Based on these aforementioned findings, we hypothesized that applying materials that reduce mechanical force, in addition to primary wound dressings, could be continuously helpful in minimizing friction and shear force at skin and wound sites. In this study, we developed a new material as a secondary dressing for reducing friction and shear force. We constructed an original experimental model to measure the interface friction force and internal shear force and pressure. A case study was conducted to propose on how to clinically use the new material for pressure injury treatment in a home-care setting.

\section{Materials and Methods}

\section{Materials}

We prepared a new rectangular-shaped $(14 \times 24 \mathrm{~cm})$, Nylon-based, nonadhesive monolayer sheet with silicone coating as a secondary dressing. The commercially available topical aid sliding sheet TASS $^{\circledR}$; Pressure Injury Research Center for Home Healthcare, Nara, Japan) was used and designated as "TASS" in this study. A transparent polyurethane film dressing (Multifix ${ }^{\circledR}$ Roll; ALCARE Co., Ltd., Tokyo, Japan) was also used as the comparison material, because it has been commonly used as a secondary dressing in wound management. ${ }^{20}$ The thickness of the TASS and the film dressing used in this study were $0.08 \mathrm{~mm}$ and $0.03 \mathrm{~mm}$, respectively.

\section{Preparation of the Skin Model}

We designed a disk-shaped, polyurethane gel-based skin model simulating the thickness, friction, and elasticity of the skin of elderly individuals. ${ }^{21-24}$ To prepare the skin model, we used a commercial two-part composite for curing polyurethane resin (Hitohada Gel; Exseal Corporation, Gifu, Japan). The compositions of the skin model are listed in Table 1. The main and curing agents were mixed vigorously and subsequently poured into a Petri dish $(\varphi, 50 \mathrm{~mm})$, in which a rectangular Teflon plate $\left(3 \times 12 \times 48 \mathrm{~mm}^{3}\right)$ was set along the equatorial axis 
Table I Compositions of the Polyurethane Gel-Based Skin Model

\begin{tabular}{|l|c|c|c|c|c|}
\hline \multirow{2}{*}{ Sample } & \multirow{2}{*}{ Compositions $^{\mathbf{a}}$} & \multirow{2}{*}{ Talc } & Thickness $^{\mathbf{b}}$ & Hardness $^{*}$ COF $^{\mathbf{c}}$ \\
\cline { 2 - 5 } & MA/CA & & $\mathbf{( c m )}$ & (Durometer Unit) \\
\hline Sample 1 & $3: 1.15$ & + & $1.0 \pm 0.1$ & $27.2 \pm 0.9$ & $0.30 \pm 0.10$ \\
\hline Sample 2 & $3: 1.20$ & + & $1.0 \pm 0.1$ & $30.5 \pm 0.4$ & $0.37 \pm 0.05$ \\
\hline Sample 3 & $3: 1.25$ & + & $1.0 \pm 0.1$ & $34.1 \pm 0.1$ & $0.33 \pm 0.06$ \\
\hline Characteristics of human skin & & $\begin{array}{l}1.5 \pm 0.5^{21)} \\
0.9 \pm 0.4^{22)}\end{array}$ & $30 \pm 1^{23)}$ & $0.30 \pm 0.05^{24)}$ \\
\hline
\end{tabular}

Notes: ${ }^{a}$ Weight ratio of main and curing agents per Petri dish $(\varphi, 50 \mathrm{~mm}) ;{ }^{b}$ thickness of skin and soft tissue; ${ }^{c}$ dynamic coefficient of friction against polytetrafluoroethylene sheet. Abbreviations: MA, main agent; CA, curing agent; COF, coefficient of friction.

at a height of $3 \mathrm{~mm}$ from the bottom of the dish. Next, the dish was warmed in a chamber at $60^{\circ} \mathrm{C}$ for 4 hours to complete curing. The molded polyurethane resin was removed from the dish, and the Teflon plate was pulled out to form a cavity. The surface of the resin was coated with talc powder to improve smoothness, and the skin model (radius, $25 \mathrm{~mm}$; height, $10 \mathrm{~mm}$ ) was completed (Figure 1A).
In addition to the skin model, following the same method used for the preparation of the skin model, we prepared a rectangular polyurethane resin sheet $(5 \times 150 \times$ $180 \mathrm{~mm}^{3}$ ) without a cavity for the friction tests. The only difference was that a rectangular dish $\left(5 \times 150 \times 180 \mathrm{~mm}^{3}\right)$ was used instead of the Petri dish. A disk-shaped polyurethane resin $(\varphi, 50 \times 10 \mathrm{~mm})$ without a cavity was also prepared for hardness testing.
A

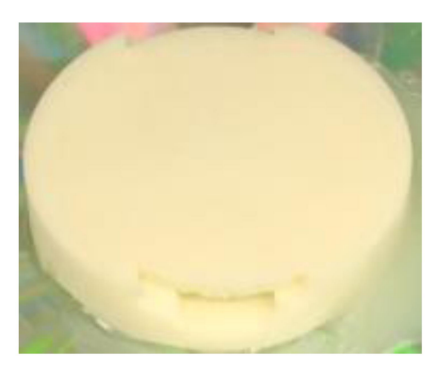

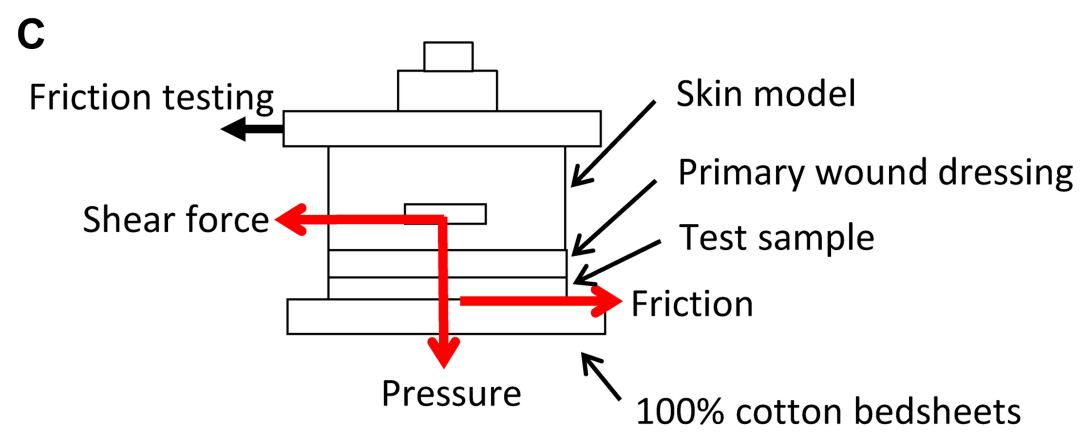

Weight with

B

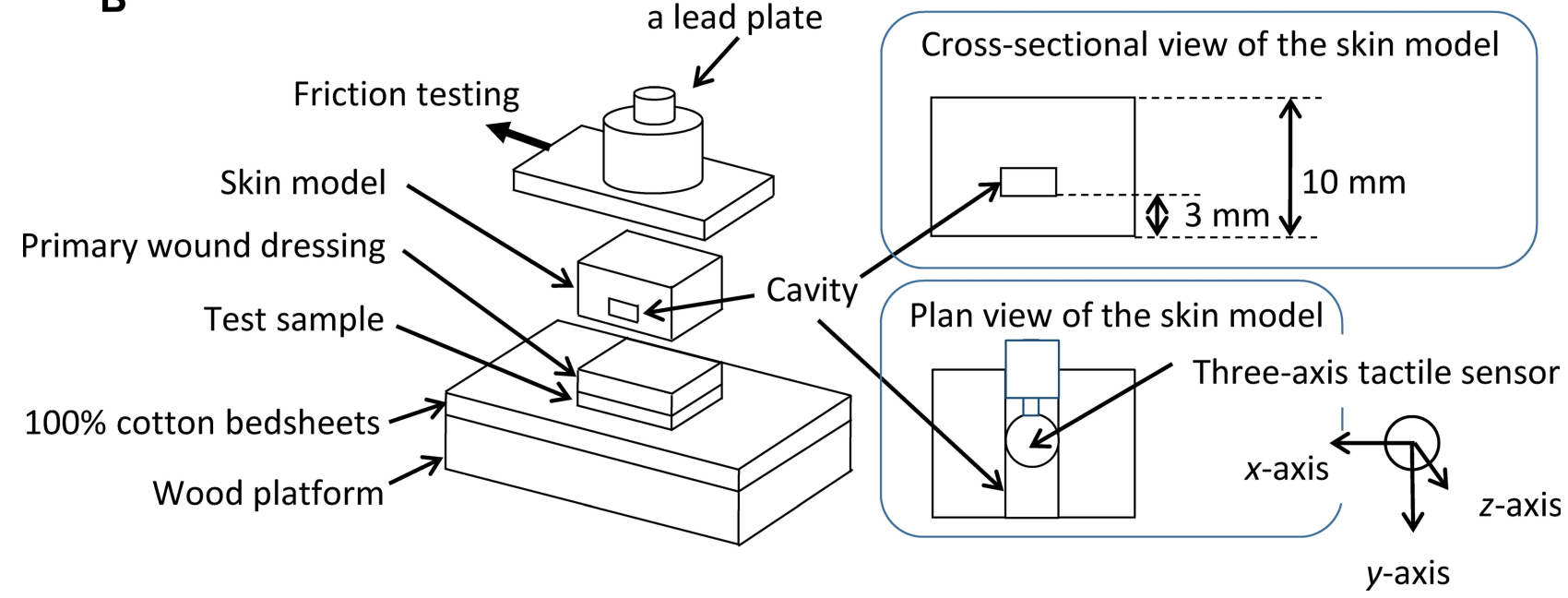

Figure I Schematic drawing of the simulated skin shearing test. (A) Photograph of polyurethane gel-based skin model. (B) Principle of operation. (C) Schematic of generation of friction, shear force, and compression stress during the simulated skin-shearing test. 


\section{Characteristics of the Skin Model}

The hardness of the skin model was tested using a durometer (Asker C-type; Kobunshi Kenki Co., Ltd., Kyoto, Japan). We used the disk-shaped polyurethane resin without a cavity as a specimen for the hardness test $(n=3)$. The data were compared with those reported in previous studies on human skin. ${ }^{23}$

To test the skin model's smoothness, a friction tester (TL20/Tt; Trinity-Lab Inc., Tokyo, Japan) was used. The rectangular-shaped polyurethane resin sheet without a cavity was used for the specimens for the smoothness test $(\mathrm{n}=5)$. According to a previous report, ${ }^{24}$ the friction force was measured against polytetrafluoroethylene (PTFE; $112 \mathrm{~g} / \mathrm{m}^{2}$ ) by covering the probe of the tester with a PTFE sheet. The tests were conducted at a contact pressure of $4 \mathrm{kPa}$, liner sliding velocity of $100 \mathrm{~mm} / \mathrm{s}$, and sliding stroke of $80 \mathrm{~mm}$.

\section{Measurement of Friction, Shear Force, and Pressure}

Friction, shear force, and pressure were measured using our original test method, designated as the "simulated skin shearing test," as shown in Figure 1B. A $5 \times 5 \mathrm{~cm}$ siliconefaced absorbent dressing (SI Aid; ALCARE Co., Ltd.) was used as a standard primary wound dressing. The skin model was covered with single or combined dressings as follows: group A, silicone-faced absorbent dressing (control group); group $\mathrm{B}$, silicone-faced absorbent dressing plus film dressing; and group $\mathrm{C}$, silicone-faced absorbent dressing plus TASS. A three-axis tactile sensor (ShokacChip ${ }^{\mathrm{TM}}$; Touchence Inc., Tokyo, Japan) was inserted and placed in the center of the cavity that had been formed in the skin model. The surface of the sensor was placed $3 \mathrm{~mm}$ above the interface of the skin model, simulating the detection of mechanical forces inside the skin tissue of elderly people, according to previous reports. $^{21,22}$

The interface friction force and internal shear force and pressure were measured under shear deformation that resulted from pulling the test probe with a bonding tester (Dage 4000Plus; Nordson Dage, Erkrath, Germany). A wood platform covered with $100 \%$ cotton bedsheets was fixed on the movable stage of the bonding tester. The test probe was placed on the wood platform so that the skin model was in contact with the bedsheets via the dressings. The test probe was weighed with a lead plate to achieve an interface pressure of $100 \mathrm{~mm} \mathrm{Hg}$, connected with the sensor of the bonding tester (load cell $<50 \mathrm{kgF}$ ) using a wire, and subsequently pulled horizontally (x-axis) on the cotton bedsheets at a rate of $0.5 \mathrm{~mm} / \mathrm{s}$ by horizontal movements of the stage. Both the pulling force of the test probe and forces ( $\mathrm{x}$ - and $\mathrm{z}$-axes) of the three-axis tactile sensor were recorded simultaneously in parallel (Figure 1C).

For data analysis, the static and dynamic coefficients of friction from the data on the test probe's pulling were calculated. Moreover, the plateaued forces detected in the directions of the $\mathrm{x}$ - and $\mathrm{z}$-axes in the dynamic condition were defined as the internal shear force and pressure, respectively. We excluded the y-axis direction from the data analysis in this study because no force was detected in the axial direction with no-sliding movement.

\section{Clinical Challenge}

A 101-year-old woman with a primary medical history of disuse syndrome was recruited from a home-care setting in Japan. The patient usually lays on the bed in the spine position. The patient had a history of pressure injury with $\mathrm{d} 2$ (ie, the Design-R scoring system defines " $\mathrm{d} 2$ " as a pressure injury with a lesion extending deep into the dermis) in the sacrum. ${ }^{25}$ A conventional pressure-redistribution mattress was already being used on her bed. The physician (Y.N.) speculated that the potential cause of pressure injury development was superficial friction with underlying shear force on repeated head-of-bed elevation. Various types of standard wound care products, including sucrose/povidone-iodine ointment, dimethyl-isopropylazulene ointment, and appropriate wound dressing, had been used to treat this patient; however, the ulcer repeatedly improved and relapsed four times before TASS was applied. Because of the limited resources of the medical reimbursement system for home-care in Japan, obtaining any more expensive therapeutic products for this patient was difficult. Thus, the physicians decided to attempt an application of TASS in addition to standard wound care. In this case, a primary wound dressing was applied directly onto the wound site. Subsequently, TASS was cut to a size wider than that of the dressing and then layered on top of the dressing. TASS was fixed directly onto the skin by sealing the opposite side with two pieces of medical adhesive tape (Figure 2). Other techniques, such as wound irrigation for biofilm control, were performed in accordance with the latest clinical guideline established by the Japan Society of Pressure Ulcers for the treatment of pressure injury. $^{26}$ 


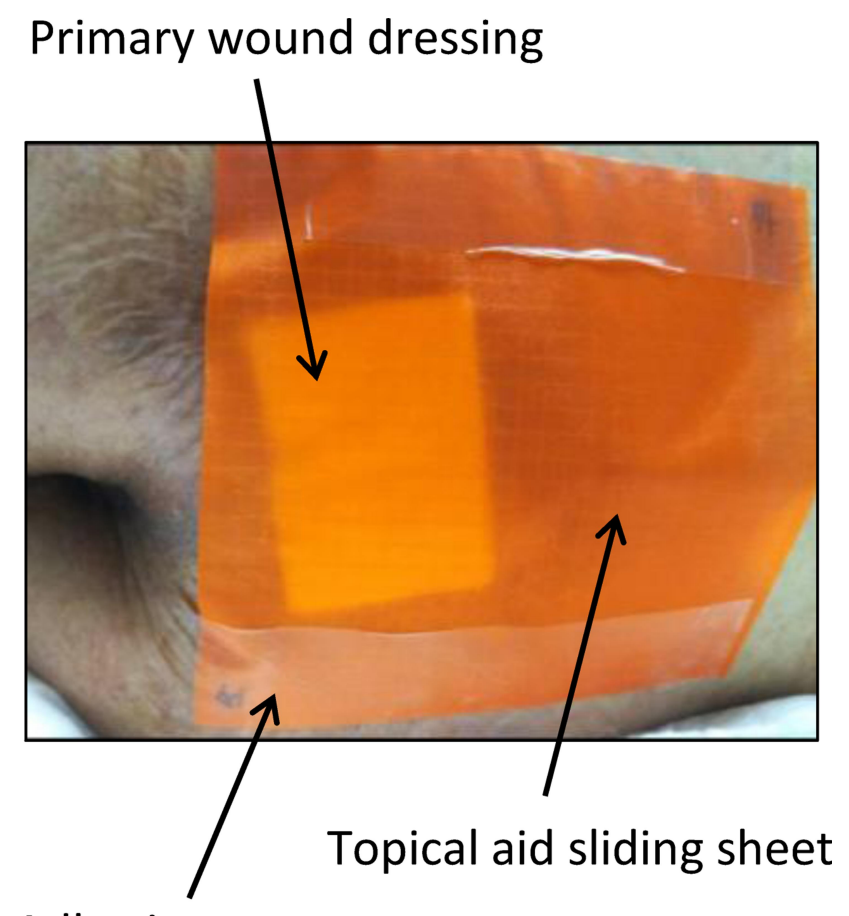

\section{Adhesive tape}

Figure 2 Photograph of the topical aid sliding sheet onto the wound site.

\section{Statistical Analysis}

The data from the interface friction and internal shear force and pressure in the simulated skin sharing test were expressed as mean \pm standard deviation (SD) $(n=5)$ and all variables were evaluated as to normally distribution by Kolmogorov-Smirnov tests. Statistical significance among groups was evaluated by one-way analysis of variance
(ANOVA) followed by Tukey's test. Statistical analysis was performed using Tukey's test. A $p$ value of $<0.05$ denoted statistically significant differences. All statistical analyses were conducted using the Statistical Package for the Social Sciences version 20.0 (IBM Corporation, Tokyo, Japan).

\section{Results}

\section{Characteristics of the Skin Model}

Thickness, hardness, and friction test results of the polyurethane gel-based skin model are represented in Table 1. From the test results, the most preferable compounding weight ratio of the main and curing agents was determined to be 3:1.20 (sample 2), because the physical properties of the skin model were seemed to be equivalent to those of the skin of elderly individuals. Thus, the sample 2 was used for the simulated skin shearing test in this study.

\section{Interface Friction Measurement}

Figure 3 shows the static and dynamic coefficient of friction that can be expressed as the force generated by friction between the surfaces divided by the normal force. The static coefficients of friction in groups $\mathrm{A}, \mathrm{B}$, and $\mathrm{C}$ were $0.42 \pm 0.03,0.38 \pm 0.02$, and $0.18 \pm 0.01$, respectively. The differences observed between group $\mathrm{C}$ and groups $\mathrm{A}$ and B were statistically significant (Figure 3A).

The dynamic coefficients of friction in groups $\mathrm{A}, \mathrm{B}$, and $\mathrm{C}$ were $0.40 \pm 0.04,0.37 \pm 0.01$, and $0.16 \pm 0.01$, respectively. The observed differences between group $\mathrm{C}$ and groups A and B were statistically significant (Figure 3B).
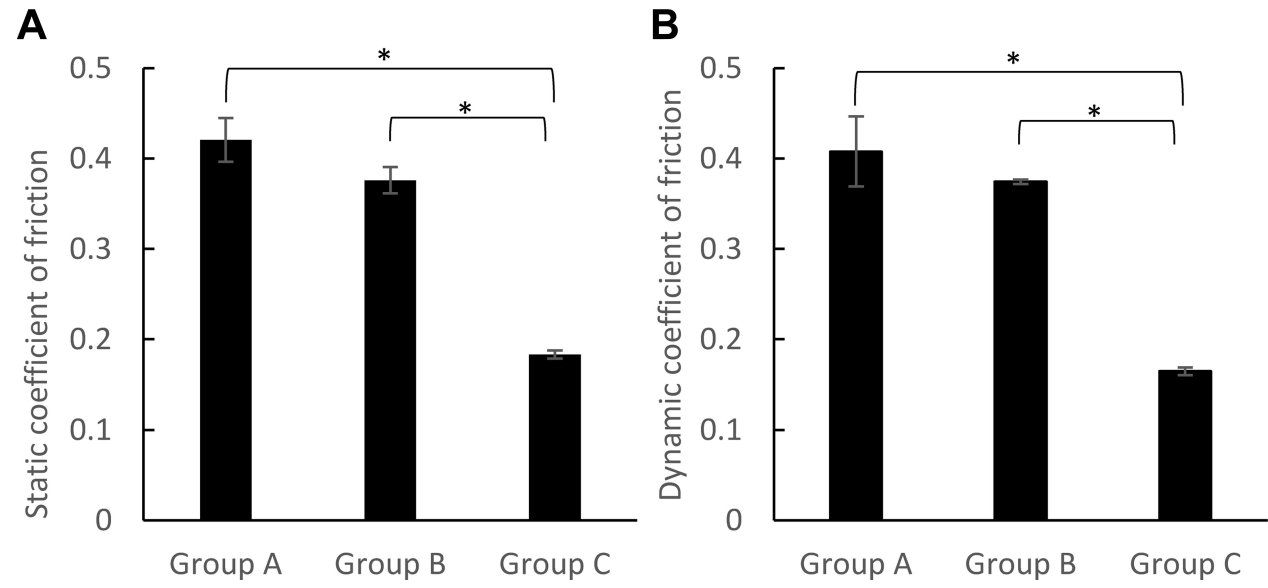

Figure 3 Static (A) and dynamic (B) coefficients of friction of each test group against 100\% cotton bedsheets. Group A, silicone-faced absorbent dressing; group B, siliconefaced absorbent dressing plus film dressing; and group $\mathrm{C}$, silicone-faced absorbent dressing plus topical aid sliding sheet. The vertical bars indicate statistically significant differences between the samples $(* p<0.05)$. 

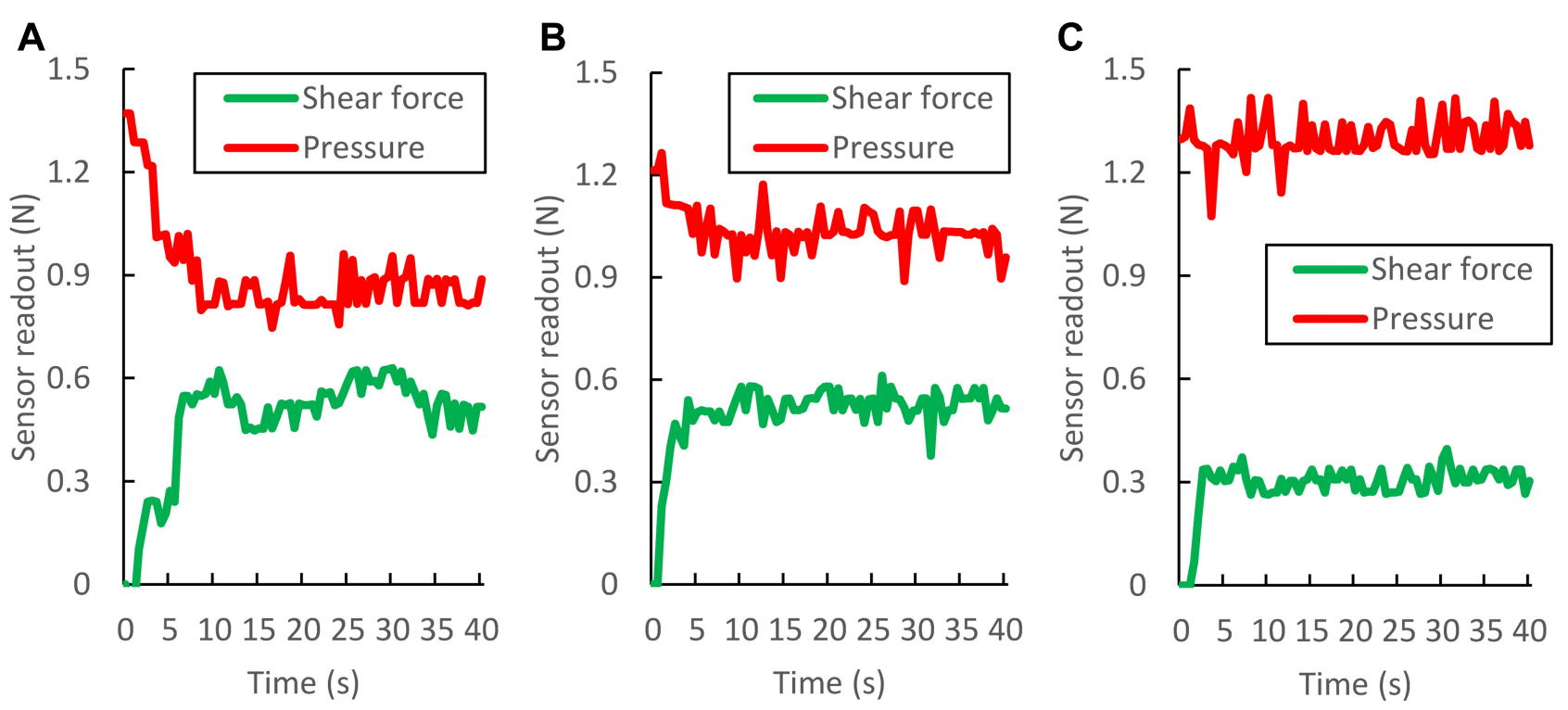

Figure 4 Representative time-dependent changes in the internal shear force and pressure generated in the skin model during horizontal pulling. A three-axis tactile sensor set in the skin model was used to measure the shear force and pressure. (A-C) are the data obtained for groups A, B, and C, respectively.

\section{Internal Shear Force and Pressure Measurement}

Figure 4 shows one actual example pertaining to the timedependent changes in internal shear force and pressure obtained by the simulated skin shearing tests. In group $\mathrm{A}$, the shear forces increased at $0-10$ seconds and then reached a near plateau (range, 0.44-0.63 N). A similar trend was observed in group B (range, 0.38-0.61 N). In contrast, the increase in shear force in group $\mathrm{C}$ terminated at only 3 seconds and then reached a near plateau (range, $0.26-0.40 \mathrm{~N}$ ). We visually observed that the slippage of the skin model on the bedsheet was initiated when the shear force reached the plateau.

The curves of the time-dependent changes in pressure were as expected (Figure 4). In groups A and B, the pressures decreased at $0-10$ seconds and then leveled off (range, 0.75-0.96 $\mathrm{N}$ and 0.89-1.17 $\mathrm{N}$, respectively). In contrast, in group $\mathrm{C}$, the intimal pressure (range, 1.14-1.41 N) was almost maintained throughout the measurements.

Figure 5 provides the results of the shear force in the dynamic condition. In group $\mathrm{C}$, the plateaued shear forces were approximately $66 \%$ and $62 \%$ of those in groups $\mathrm{A}$ and $\mathrm{B}$, respectively. The differences observed between group $\mathrm{C}$ and groups $\mathrm{A}$ and $\mathrm{B}$ were statistically significant.

\section{Case}

Figure 6 presents the time course of wound healing after the intervention with TASS. A d2 sacral pressure injury

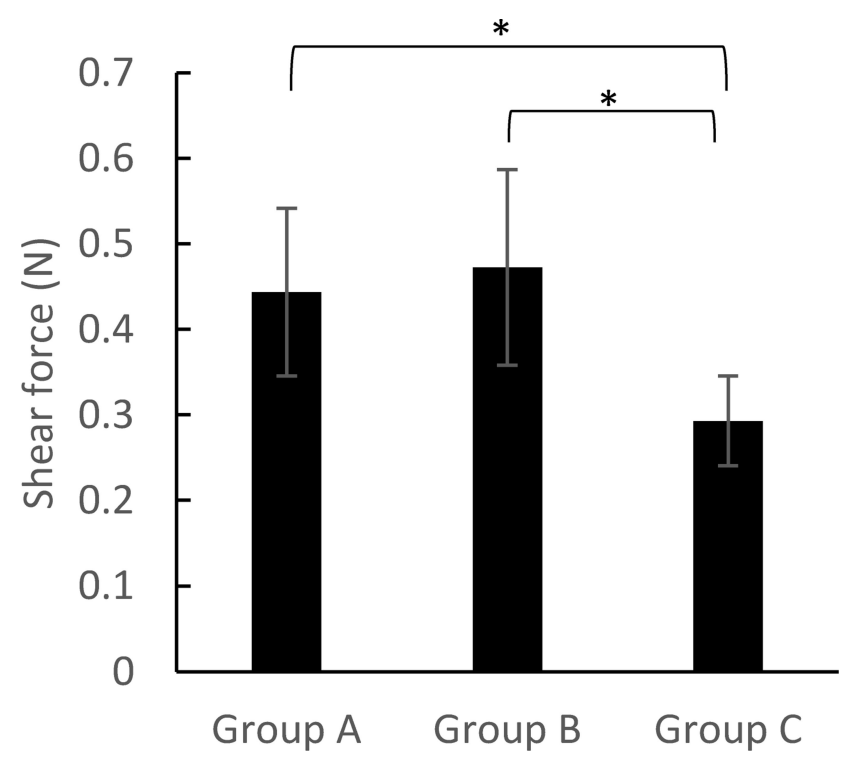

Figure 5 Internal shear forces obtained by the simulated skin shearing test. Averaged internal shear force in the measurement time ranging from 10 to 40 seconds. The vertical bars indicate statistically significant differences between the samples $(* p<0.05)$.

was observed at the time of study initiation (Figure 6A). A 5-day application resulted in complete epithelization with decreasing wound area (Figure 6B). After the healing process was complete, standard preventive care without TASS was provided to prevent pressure injury recurrence. However, 6 months after healing, a $\mathrm{d} 2$ pressure injury appeared in a similar location in the sacral region (Figure 6C). TASS reapplication for 7 days resulted in complete epithelization (Figure 6D). The patient has not reported 

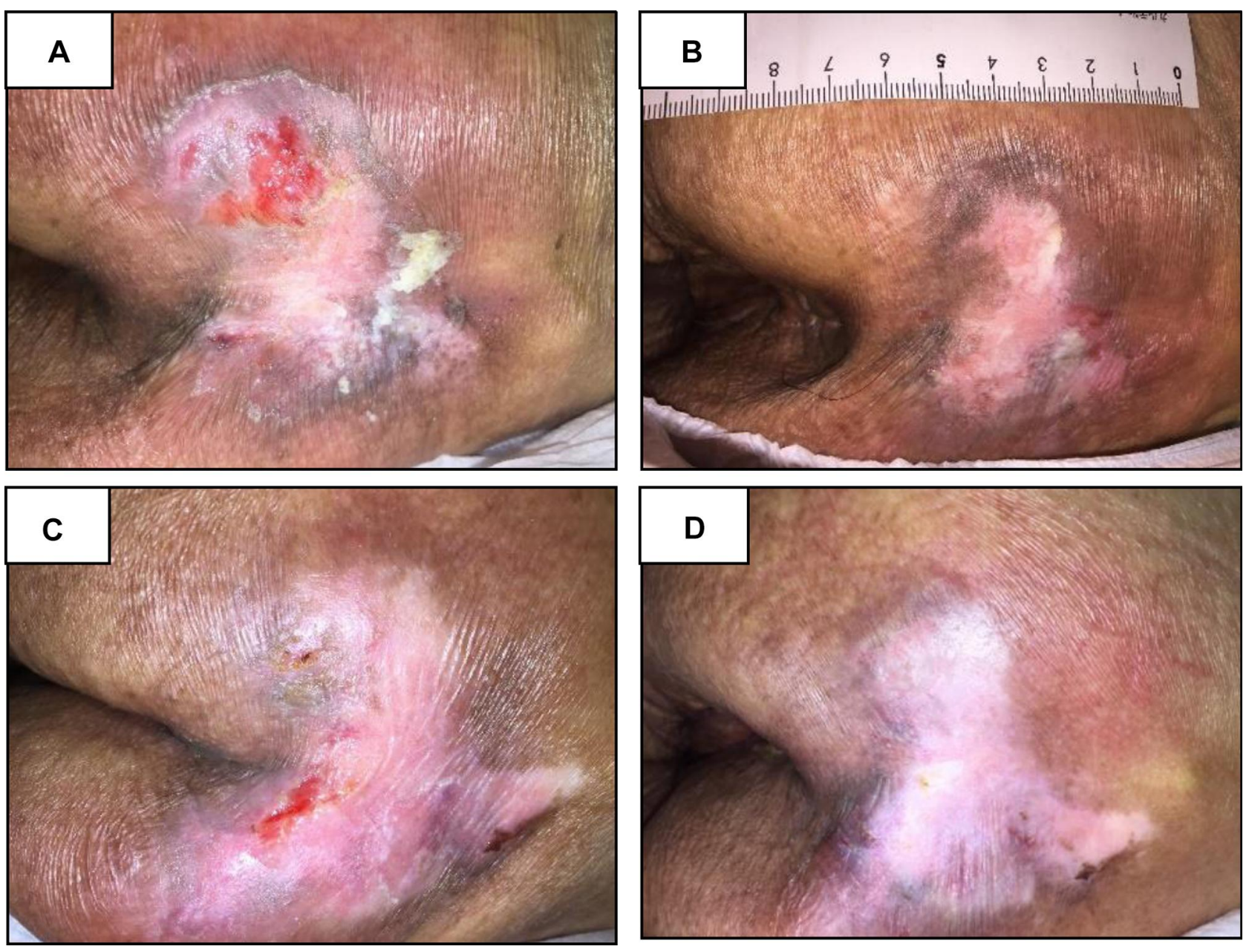

Figure 6 Images of pressure injury treatment using a primary wound dressing plus the topical aid sliding sheet. (A) A sacral pressure injury classified as d2 (region extended to the dermis) by the Design-R scoring system was generated. (B) The topical aid sliding sheet was used for 5 days. (C) A new $\mathrm{d} 2$ pressure injury was generated on a similar location at the sacrum. (D) The topical aid sliding sheet was reapplied onto the wound site via a dressing for 7 days; epithelization was subsequently completed.

any wound-related complications. In this case, the dressing had never come off from the adhesive tape.

\section{Discussion}

The management of friction, shear force, pressure, and their combined actions is important for successfully preventing and treating pressure injury. ${ }^{1}$ The clinical effectiveness of prophylactic dressings for pressure injury prevention has been well established; however, information on using mechanical force-reducing materials during pressure injury treatment is little. This study revealed the efficacy of TASS for reducing friction, shear force, and their combined actions, suggesting that TASS can become a new valuable solution during topical treatment of pressure injury.

The most important finding of this study was that the internal shear force was significantly reduced in group
$\mathrm{C}$ as compared with groups $\mathrm{A}$ and $\mathrm{B}(p<0.05$; Figure 5), which might be due to the reduction of interface static and dynamic friction coefficients by TASS (Figure 3). In contrast, groups $\mathrm{A}$ and $\mathrm{B}$ exhibited higher shear stress during the pulling of the skin model, because of the higher friction coefficients. These findings suggest that using TASS can help reduce the internal shear stress at ulcer sites caused by patient movement.

Figure 7 illustrates the effect of TASS on reducing friction and shear force. The actual force loaded on the skin model results from the combination of the forces of the $\mathrm{x}$ - and z-axes and is ultimately imaged as a vector. The results obtained from this study indicate a difference in force directions between groups A and B and group C in the dynamic condition, whereas the magnitude of the force between the groups might be similar. Because of a strong shear force-reducing effect by TASS, the force of the 


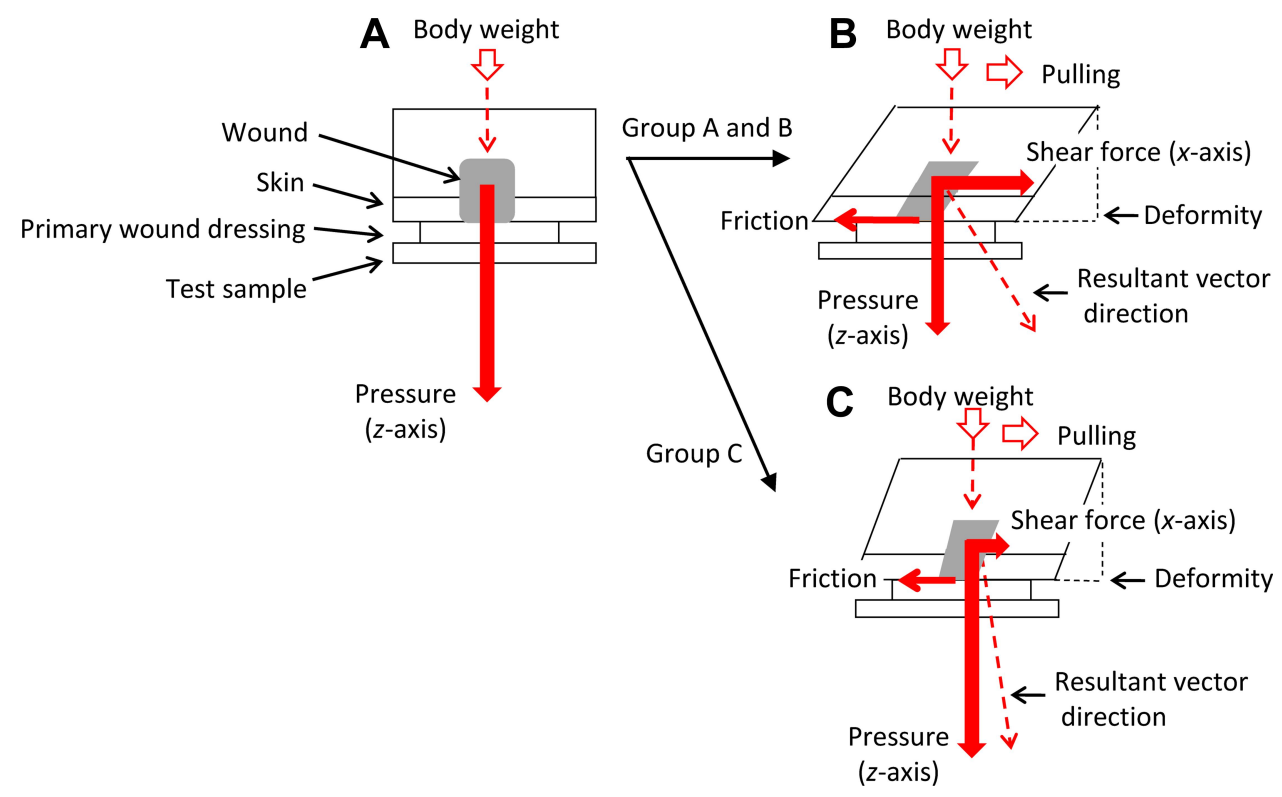

Figure 7 The effect on friction and shear force in each test group is illustrated based on the results of the simulated skin shearing test. (A) Only static pressure was loaded for all test groups in a static condition (no pulling of the skin model). (B and C) A combination of shear force and pressure was loaded in a dynamic condition (pulling the skin model). The difference in the resultant vector direction between groups $A$ and $B$ and group $C$ is represented.

z-axis is speculated to be greater in group $\mathrm{C}$ in the dynamic condition. Less shear force affects less shape changes of the skin model during movement, and then the force detected by the sensor in the z-axis direction may keep to be higher. This finding may imply that using TASS is preferable in treating pressure injuries primarily caused by shear force, more so than injuries caused by pressure with minimal shearing.

It should be noted that TASS itself is not capable of reducing pressure during pulling of the skin model (Figure 4). Therefore, in real-world clinical settings, a combination of TASS and pressure-relieving support surfaces (ie, hightech mattresses and cushions) would be better for the reduction of both internal shear force and pressure. It is expected that a combination use of TASS and any support surfaces can contribute not only to changing the force direction but also to reducing the magnitude of the force in the simulated skin shearing test. Further experiments are required to clarify which types of pressure-relieving support surfaces are more compatible with TASS for pressure injury treatment.

The generation of shear force affects the stretching of blood vessels, which reduces blood flow and results in the generation of ischemic necrotic tissue that can delay wound healing. ${ }^{27,28}$ Previous studies have indicated that pressure level sufficient to occlude blood flow was reduced when simultaneous shear force was applied, ${ }^{29-31}$ indicating that the shear force can reduce the pressure required to generate a breakdown of soft tissue. As an example of an actual situation, it is well known that repeated shear force with pressure between a patient's body and contact objects occurs when using head-of-bed elevation. ${ }^{11}$ To protect a pressure injury and allow sliding on the surface of it by shear force-reducing material such as TASS could be expected to bring more beneficial of protecting the patient from secondary infection, pain, and discomfort at the wound site and its surrounding skin.

It is important to understand that the repeated frictional forces and resultant shear forces cause skin tissue damage associated with pressure injury development. Reportedly, shear force on heel in elderly individuals was reduced by the use of dressing with low frictional outer layer. ${ }^{32}$ Despite some relationship between interface friction force and internal shear force, it remains unclear how different levels of frictional forces result in skin damage accumulation. The authors consider that this clinical question can be resolved if the effect of skin tissue damage on different levels of repeated friction force is tested in an additional research.

Because TASS is versatile, it is expected that its application will expand to a variety of clinical settings, ranging from acute care to home-care. As a first step, the authors focused on the treatment of pressure injury in a home-care setting, because pressure injury problems are serious 
among elderly individuals at home or within their community, more so than in patients in an acute care hospital. ${ }^{33}$ In addition, the value of the characteristics of TASS can be maximized in the clinical situation of home-care. In this study, a protocol on how to clinically use the TASS was proposed in the treatment of pressure injury at a home care. More clinical studies with more participants will be needed for clarifying the clinical safety and efficacy of TASS in the future. The authors speculate that severe (eg, Stage 3 and 4) pressure injury and cavity wound are considered to be the most suitable for this treatment because of the strong internal shear force-reducing effect of TASS

An additional clinical point of view, namely, the timing of the TASS intervention, is important for pressure injury management. Physicians occasionally select a surgical procedure, such as debridement, when the presence of necrotic tissue or biofilm is confirmed as a significant risk factor for delayed wound healing. ${ }^{34,35}$ The physician in this study (Y.N.) suggested that using TASS should be initiated immediately after completing surgical procedure. The continuous use of TASS at the wound site may be effective in increasing cell proliferation, tissue granulation, and reepithelialization, leading to complete wound healing without further delay.

Our testing philosophy consists of using a biomimetic test method, rather than a standard test method, to simulate the actual clinical environment. Previous reports on the preparation and evaluation of a skin model based on synthetic polymer materials for biomechanical applications have been published. ${ }^{36-39}$ Among the available materials, a soft polyurethane substrate was used in this study to simulate the physical properties of the human skin. The friction coefficient and elastic modules of the skin model were set to be similar to those of the skin of elderly individuals, who are often at risk of pressure injury development. Considering the effects of a bony prominence is also important when investigating ulcer management. However, to simplify the skin model for evaluating interface friction and internal shear force and pressure, we did not consider a bony prominence in this study. In future research, we will be able to investigate the reduction of mechanical stress at the site of a bony prominence using the skin model prepared in this study.

It is well known that external pressure of more than $32 \mathrm{~mm} \mathrm{Hg}$ occludes the blood vessel and the occlusion for a critical duration can lead to tissue necrosis followed by pressure injury development. ${ }^{40}$ Actually, compression stress at a site of pressure injury has been reported in the range of 18 to $186 \mathrm{mmHg}$, depending on the patient's physical characteristics and mattress selection. ${ }^{41}$ Hence, the applied compression stress of $100 \mathrm{mmHg}$ in the simulated skin shearing test is considered to be accepted as a biomimetic test method. Also, the authors speculate that strain fields in the skin model used in this study are equivalent compared with those in the patient's tissue, because the skin model mimicking the mechanical properties of human skin has been employed in the simulated skin shearing test.

We believe that this study is the first step of a new approach to friction and shear force reduction at skin and wound sites for the treatment of pressure injury. Further studies are warranted to investigate the mechanical force-reducing effects of TASS at bony prominence sites using the skin model, verify the combination effect of TASS and pressure-redistribution support surfaces for reducing mechanical forces, and perform a clinical trial with a larger sample size to verify the effectiveness of TASS.

\section{Conclusion}

TASS significantly reduced the interface friction and internal shear forces using a skin model. From the case study, TASS had the potential to apply as a secondary dressing for pressure injury treatment at a home care.

\section{Abbreviations}

PTFE, polytetrafluoroethylene; TASS, topical aid sliding sheet.

\section{Data-Sharing Statement}

The data set used in this study is available from the corresponding author upon reasonable request.

\section{Ethics Approval and Consent to Participate}

This study was approved by the Institutional Review Board of Tenri hospital, Nara, Japan (Number: 1069). Written informed consent was obtained from participant. The patient, or legal representative of the patient, provided informed consent for the case details and accompanying images to be published. All aspects of this research were in accordance with the principles set forth by the Declaration of Helsinki. 


\section{Acknowledgments}

The authors thank Enago for English language editing service. This experimental study was conducted by a funding from ALCARE.

\section{Author Contributions}

All authors substantially participated in the conception, study design, data collection, and data analysis. All authors also contributed to drafting the manuscript and critical revisions for important intellectual content and gave their final approval for the version to be published. Finally, all authors agreed to be accountable for all aspects of this work to ensure that questions related to the accuracy or integrity of any part of this work would be appropriately investigated and resolved.

\section{Disclosure}

M.K. is an employee of ALCARE Co., Ltd (Tokyo, Japan). Y.N. is the chief of Pressure Injury Research Center for Home Healthcare (Nara, Japan). The authors have no other conflicts of interest to disclose related to this work.

\section{References}

1. Heasler E. European pressure ulcer advisory panel, National pressure injury advisory panel and Pan Pacific pressure injury alliance. Prevention and treatment of pressure ulcers/injuries: clinical practice guideline. EPUAP/NPIAP/PPPIA. The International Guideline; 2019.

2. Doridam J, Macron A, Vergari C, Verney A, Rohan PY, Pillet H. Feasibility of sub-dermal soft tissue deformation assessment using B-mode ultrasound for pressure ulcer prevention. J Tissue Viability. 2018;27(4):238-243. doi:10.1016/j.jtv.2018.08.002

3. Karg P, Ranganathan VK, Churilla M, Brienza D. Sacral skin blood flow response to alternating pressure operating room overlay. $J$ Tissue Viability. 2019;28(2):75-80. doi:10.1016/j.jtv.2019.03.001

4. Razmus I, Bergquist-Beringer S. Pressure ulcer risk and prevention practices in pediatric patients: a secondary analysis of data from the national database of Nursing Quality Indicators ${ }^{\circledR}$. Ostomy Wound Manage. 2017;63(2):28-32.

5. Wu X, Li Z, Cao J, et al. The association between major complications of immobility during hospitalization and quality of life among bedridden patients: a 3 month prospective multi-center study. PLoS One. 2018;13(10):e0205729. doi:10.1371/journal.pone.0205729

6. Padula WV, Delarmente BA. The national cost of hospital-acquired pressure injuries in the United States. Int Wound J. 2019;16 (3):634-640. doi:10.1111/iwj.13071

7. Al Mutairi K, Hendrie D. Global incidence and prevalence of pressure injuries in public hospitals: a systematic review. Wound Med. 2018;22:23-31. doi:10.1016/j.wndm.2018.05.004

8. Sprigle $\mathrm{S}$, Sonenblum S. Visualizing tissue strain under the sacrum and coccyx in different supine postures: a case series. Adv Skin Wound Care. 2019;32(6):264-271. doi:10.1097/01.ASW.00005 54445.59743 .44

9. Manderlier B, Damme NV, Verhaeghe S, et al. Modifiable patient-related factors associated with pressure ulcers on the sacrum and heels: secondary data analyses. $J$ Adv Nurs. 2019;75 (11):2773-2785. doi:10.1111/jan.14149
10. Ohura T, Takahashi M, Mimura M, Okazaki H, Kajiwara R. [Change of surface pressure and the shear force whole raising/lowering the upper body]. Jpn J PU. 2007;9(1):21-27. Japanese.

11. Mimura M, Ohura T, Takahashi M, Kajiwara R, Ohura N. Mechanism leading to the development of pressure ulcers based on shear force and pressures during a bed operation: influence of body types, body positions, and knee positions. Wound Repair Regen. 2009;17(6):789-796. doi:10.1111/j.1524-475X.2009.00540.x

12. Ohura T, Takahashi M, Ohura N. Influence of external forces (pressure and shear force) on superficial layer and subcutis of porcine skin and effects of dressing materials: are dressing materials beneficial for reducing pressure and shear force in tissues? Wound Repair Regen. 2008;16(1):102-107. doi:10.1111/j.1524-475X.2007.00325.x

13. Rae KE, Isbel S, Upton D. Support surfaces for the treatment and prevention of pressure ulcers: a systematic literature review. $J$ Wound Care. 2018;27(8):467-474. doi:10.12968/jowc.2018.27.8.467

14. Bååth C, Idvall E, Gunningberg L, Hommel A. Pressure-reducing interventions among persons with pressure ulcers: results from the first three national pressure ulcer prevalence surveys in Sweden. J Eval Clin Pract. 2014;20(1):58-65. doi:10.1111/jep.12079

15. Kohta M, Sakamoto K, Oh-i T. Polyurethane film dressings and ceramide 2-containing hydrocolloid dressing reduce the risk of pressure ulcer development in high-risk patients undergoing surgery: a matched case-control study. Chronic Wound Care Manage Res. 2015;2:23-30. doi:10.2147/CWCMR.S77087

16. Kohta M, Sakamoto K, Kawachi Y, Oh-i T. A single-center, prospective, randomized, open label, clinical trial of ceramide 2-containing hydrocolloid dressings versus polyurethane film dressings for pressure ulcer prevention in high risk surgical patients. Chronic Wound Care Manage Res. 2015;2:171-179. doi:10.2147/CWCMR.S93555

17. Yoshimura M, Ohura N, Tanaka J, et al. Soft silicone foam dressing is more effective than polyurethane film dressing for preventing intraoperatively acquired pressure ulcers in spinal surgery patients: the Border Operating room Spinal Surgery (BOSS) trial in Japan. Int Wound J. 2018;15(2):188-197. doi:10.1111/iwj.12696

18. Matsuzaki K, Kishi K. Investigating the pressure-reducing effect of wound dressings. $J$ Wound Care. 2015;24(11):512-517. doi:10.12968/jowc.2015.24.11.512

19. Call E, Pedersen J, Bill B, et al. Enhancing pressure ulcer prevention using wound dressings: what are the modes of action? Int Wound J. 2015;12(4):408-413. doi:10.1111/iwj.12123

20. Sakamoto K, Kato Y, Kohta M. A prospective cohort study of risk factors for skin disorders at the margins of surgical wound dressing. J Jpn WOCN. 2017;21(3):266-272.

21. Sugimoto Y, Koyama E, Mori M. Thickness and pressure deformability of soft tissue over the sacrum in elderly and young subjects. J Jap Soc Nurs Res. 2004;27(2):39-43.

22. Sanada H, Nagakawa T, Sugama J, et al. The significance of the relationship between the degree of bony prominences and pressure ulcer development in elderly patients. J Jpn Asso ET Nurs. 1997;1:34-41.

23. Falanga V, Bucalo B. Use of a durometer to assess skin hardness. J Am Acad Dermatol. 1993;29(1):47-51. doi:10.1016/0190-9622(93) 70150-R

24. Gerhardt LC, Lenz A, Spencer ND, Münzer T, Derler S. Skin-textile friction and skin elasticity in young and aged persons. Skin Res Technol. 2009;15(3):288-298. doi:10.1111/j.1600-0846.2009.00363.x

25. Matsui Y, Furue M, Sanada H, et al. Development of the DESIGN-R with an observational study: an absolute evaluation tool for monitoring pressure ulcer wound healing. Wound Rep Regen. 2011;19(3):309-315. doi:10.1111/j.1524-475X.2011.00674.X

26. The Japanese Society of Pressure Ulcers Revision Committee. JSPU guidelines for the prevention and management of pressure ulcers. Jpn J PU. 2016;18(4):455-544.

27. Liao F, Burns S, Jan YK. Skin blood flow dynamics and its role in pressure ulcers. J Tissue Viability. 2013;22(2):25-36. doi:10.1016/j. jtv.2013.03.001 
28. Cui F, Pan Y, Xie H, et al. Pressure combined with ischemia/reperfusion injury induces deep tissue injury via endoplasmic reticulum stress in a rat pressure ulcer model. Int J Mol Sci. 2016;17(3):284. doi:10.3390/ijms 17030284

29. Bennet L, Kavner D, Lee BK, Trainor FA. Shear vs pressure as causative factors in skin blood flow occlusion. Arch Phys Med Rehabil. 1979;60(7):309-314.

30. Polliack AA, Scheinberg S. A new technology for reducing shear and friction forces on the skin: implications for blister care in the wilderness setting. Wilderness Environ Med. 2006;17:109-119. doi:10.1580/PR30-05.1

31. Takahashi M, Shitamichi M, Ohura T. [Effecs of pressure and shear force on radial artery and skin capillary blood flow]. Jpn $J P U$. 2012;14(4):547-552. Japanese.

32. Nakagami G, Sanada H, Konya C, Kitagawa A, Tadaka E, Tabata K. Comparison of two pressure ulcer preventive dressings for reducing shear force on the heel. JWOCN. 2006;33(3):267-272.

33. Nakashima S, Yamanashi H, Komiya S, Tanaka K, Maeda $T$. Prevalence of pressure injuries in Japanese older people: a population-based cross-sectional study. PLoS One. 2018;13(6): e0198073. doi:10.1371/journal.pone.0198073

34. Schiffman J, Golinko MS, Yan A, Flattau A, Tomic-Canic M, Brem H. Operative debridement of pressure ulcers. World J Surg. 2009;33(7):1396-1402. doi:10.1007/s00268-009-0024-4
35. Mori Y, Nakagami G, Kitamura A, et al. Effectiveness of biofilm-based wound care system on wound healing in chronic wounds. Wound Rep Regen. 2019;27(5):540-547. doi:10.1111/ wrr. 12738

36. Dąbrowska AK, Rotaru GM, Derler S, et al. Materials used to simulate physical properties of human skin. Skin Res Technol. 2016;22(1):3-14. doi:10.1111/srt.12235

37. Shimizu R, Nonomura Y. Preparation of artificial skin that mimics human skin surface and mechanical properties. J Oleo Sci. 2018;67 (1):47-54. doi:10.5650/jos.ess 17152

38. Lir I, Haber M, Dodiuk-Kenig H. Skin surface model material as a substrate for adhesion-to-skin testing. J Adhes Sci Tech. 2007;21 (15):1497-1512. doi:10.1163/156856107782844783

39. Jachowicz J, McMullen R, Prettypaul D. Indentometric analysis of in vivo skin and comparison with artificial skin models. Skin Res Tech. 2007;13(3):299-309. doi:10.1111/j.1600-0846.2007.00229.x

40. Landis E. Microinjection studies of the capillary blood pressure in human skin. Heart. 1930;15:209-228.

41. Sato A, Sugama J, Sanada H, Okuwa M, Tamai N, Kawasaki M. The cost-effectiveness of a double-layer air-cell mattress for treating pressure ulcers. Jpn J PU. 2006;8(2):140-147.
Chronic Wound Care Management and Research

\section{Publish your work in this journal}

Chronic Wound Care Management and Research is an international, peer reviewed, open access, online journal publishing original research, reviews, editorials, and commentaries on the causes and management of chronic wounds and the major issues related to chronic wound management. Topics also include chronic wounds as comorbidities to
Dovepress

other conditions, patient adherence to therapy, and the economic burden of chronic wounds. The manuscript management system is completely online and includes a very quick and fair peer review system, which is all easy to use. Visit http://www.dovepress.com/ testimonials.php to read real quotes from published authors. 